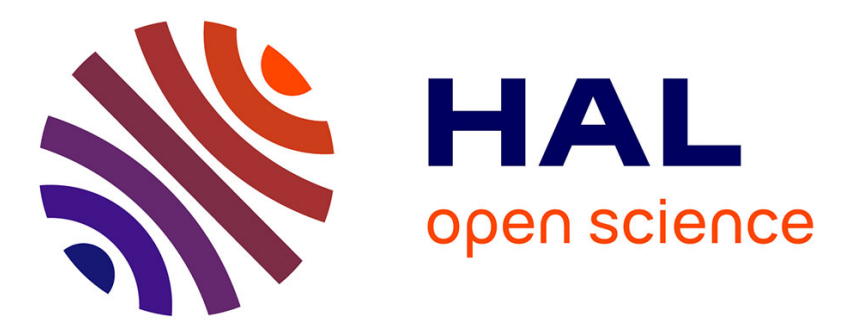

\title{
Efficient amorphous platinum catalyst cluster growth on porous carbon: A combined Molecular Dynamics and experimental study
}

Lu Xie, Pascal Brault, Christophe Coutanceau, Jean-Marc Bauchire, Amaël Caillard, Steve Baranton, Johannes Berndt, Erik Neyts

\section{To cite this version:}

Lu Xie, Pascal Brault, Christophe Coutanceau, Jean-Marc Bauchire, Amaël Caillard, et al.. Efficient amorphous platinum catalyst cluster growth on porous carbon: A combined Molecular Dynamics and experimental study. Applied Catalysis B: Environmental, 2015, 162, pp.21-26. 10.1016/j.apcatb.2014.06.032 . hal-01016051

\section{HAL Id: hal-01016051 https://hal.science/hal-01016051}

Submitted on 27 Jun 2014

HAL is a multi-disciplinary open access archive for the deposit and dissemination of scientific research documents, whether they are published or not. The documents may come from teaching and research institutions in France or abroad, or from public or private research centers.
L'archive ouverte pluridisciplinaire HAL, est destinée au dépôt et à la diffusion de documents scientifiques de niveau recherche, publiés ou non, émanant des établissements d'enseignement et de recherche français ou étrangers, des laboratoires publics ou privés. 


\section{Efficient amorphous platinum catalyst cluster growth on porous carbon: A combined Molecular Dynamics and experimental study}

Lu Xie ${ }^{1,2}$, Pascal Brault ${ }^{1, *}$, Christophe Coutanceau ${ }^{3}$, Jean-Marc Bauchire ${ }^{1}$, Amael Caillard ${ }^{1}$, Steve Baranton ${ }^{2}$, Johannes Berndt ${ }^{1}$, Erik C. Neyts ${ }^{4}$

${ }^{1}$ GREMI, UMR7344 CNRS Université d'Orléans BP6744, 45067 Orléans Cedex 2, France

${ }^{2}$ School of Physics and Nuclear Energy Engineering, BeiHang University XueYuan Road No.37, HaiDian District, Beijing 100191, China

${ }^{3}$ Université de Poitiers, IC2MP, UMR7285 CNRS, 86073 Poitiers Cedex 9, France

${ }^{4}$ Department of Chemistry, Research Group PLASMANT, University of Antwerp, BE-2610 Antwerp-Wilrijk, Belgium

\section{*Corresponding author: Pascal.Brault@univ-orleans.fr}

Abstract: Amorphous platinum clusters supported on porous carbon have been envisaged for high-performance fuel cell electrodes. For this application, it is crucial to control the morphology of the Pt layer and the $\mathrm{Pt}$ - substrate interaction to maximize activity and stability. We thus investigate the morphology evolution during Pt cluster growth on a porous carbon substrate employing atomic scale molecular dynamics simulations. The simulations are based on the Pt-C interaction potential using parameters derived from Density Functional Theory and are found to yield a Pt cluster morphology similar to that observed in low loaded fuel cell electrodes prepared by plasma sputtering. Moreover, the simulations show amorphous $\mathrm{Pt}$ cluster growth in agreement with X-ray diffraction and Transmisson Electron Microscopy experiments on high performance low Pt content $\left(10 \mu \mathrm{g}_{\mathrm{Pt}} \mathrm{cm}^{-2}\right)$ loaded fuel cell electrodes and provide a fundamental insight in the cluster growth mechanism.

Keywords: Molecular dynamics; plasma sputtering deposition; cluster growth; Pt catalyst; fuel cell electrodes 


\section{Introduction}

Physical and electronic properties of metal clusters deposited on various substrates have recently received a great deal of attention. Noble metal clusters, particularly $\mathrm{Ru}, \mathrm{Rh}, \mathrm{Pd}, \mathrm{Pt}$ and $\mathrm{Au},{ }^{[1]}$ are very often used in catalytic reactions. ${ }^{[2,3]}$ In heterogeneous catalysis, reactions occur at the catalyst surface, so that a high surface-to-volume ratio leading to a large fraction of accessible atoms is required for increasing the activity of the catalyst ${ }^{[4-6]}$, and for decreasing its cost. There is thus a real interest to obtain the highest catalytic surface area from a low metal weight. Currently, a very important application of noble metals is their use for activating electrochemical reactions occurring in proton exchange membrane fuel cells (PEMFCs),${ }^{[7-9]}$ such as the sluggish oxygen reduction reaction. ${ }^{[10,11]}$ In this latter case, Ptbased clusters are supported by nanostructured carbon substrates, among them disordered porous carbon structures ${ }^{[12,13]}$ and ordered carbon structures, such as nanotubes (CNTs)/carbon nanofibers (CNFs). ${ }^{[14,15]}$

Lee et al. reported on the Pt cluster size distribution as a function of Pt loading for electrodeposited Pt nanocrystal on highly orientated pyrolytic graphite (HOPG) surfaces and demonstrated that the average cluster size increased as the Pt loading increased, ${ }^{[16]}$ resulting in the decrease of the active surface area. Several methods were proposed for lowering the Pt loading: by alloying $\mathrm{Pt}$ with foreign metal atoms, ${ }^{[17,18]}$ by forming Pt-based core-shell structures, ${ }^{[19,20]}$, by localizing the catalytic particle close to the proton conductive solid electrolyte, ${ }^{[21]}$ by modifying Pt cluster surface with a proton conductive polymer, ${ }^{[22,23]}$ etc. One of the major degradation factors of the electrical performances of PEMFC electrodes however is the agglomeration process of metal clusters under fuel cell working conditions, ${ }^{[24,25]}$ due to their mobility on the carbon supports. ${ }^{[26]}$ It is then necessary to keep the Pt clusters well attached to and dispersed on the nanostructured carbon support to avoid their agglomeration over time, which would lead to the loss of surface area and mass 
activity. ${ }^{[27]}$ However, Clark and Kesmodel ${ }^{[28]}$ studied very small Pt clusters in the order of a few $\mathrm{nm}$ and demonstrated that their migration over the nanoporous surface leads to coalescence which in turn leads to the formation of a more stable and larger cluster. Accordingly, Lee et al. ${ }^{[16]}$ reported that the diameter distribution of mobile Pt clusters have a maximum around $14 \mathrm{~nm}$. The morphology, microstructure and interaction with the support of the metal clusters are therefore properties recognized as driving the activity and stability of the catalyst. Many efforts are then directed at optimizing the catalytic performance, which in turn requires a thorough understanding of both the relationship between the nanocatalyst deposition process and the nanocatalyst activity, as well as the $\mathrm{Pt}-$ substrate interactions $^{[29,30]}$. The ability to predict - and ultimately - design stable and highly active Pt clusters supported on a porous carbon substrate is thus of paramount importance. Classical reactive molecular dynamics (MD) simulations was used to investigate the dynamical and structural evolution of platinum cluster growth on a nanostructured porous carbon substrate at the atomic scale by a plasma sputtering method. Such metal deposition method has proven to be very efficient for the preparation of highly active low Pt loaded PEMFC electrodes. ${ }^{[31-33]}$

We will demonstrate how these atomic scale simulations provide insight in the influence of the deposition conditions on the cluster growth and the resulting Pt morphology. Finally, we develop a plasma method for preparing Pt cluster deposited on carbon and provide a comparison between our simulation results and experimental results on the structural and morphological evolution of the Pt-clusters during the growth, which are leading to high performance fuel cell electrodes.

\section{Experimental}

The deposition chamber is equipped with two rectangular targets: one of pure carbon and one of $\mathrm{Pt}_{0.01} \mathrm{C}_{0.99}$. Deposition conditions are as follows: power $530 \mathrm{~W}$, target voltage $700 \mathrm{~V}$, and 
target current $0.78 \mathrm{~A}$. The growth rate is $4 \mathrm{~nm} \cdot \mathrm{min}^{-1}$. The target-to-substrate distance is $6.5 \mathrm{~cm}$. Targets are $45^{\circ}$ tilted with respect to the substrate. Conventional uncatalyzed E-Tek carbon porous layers (CPL) on a carbon woven web are used as substrates. Electrodes are loaded at $0.010 \mathrm{mg} \mathrm{cm}_{\mathrm{Pt}}^{-2}$. The Pt loading and localization profile inside the CPL was determined by performing Rutherford backscattering spectroscopy: 90\% of Pt atoms were localized in the first $200 \mathrm{~nm}$ depth of the material.

TEM images were obtained using a JEOL JEM 2010 (equipped with a LaB6 filament and with a resolution of $0.35 \mathrm{~nm}$ ). The size distribution was estimated from the determination of the diameter from 100 particles using ImageJ free software ${ }^{[34]}$.

The XRD measurements were performed on a Bruker D 5005 Bragg-Brentano diffractometer operated with a copper tube powered at $40 \mathrm{kV}$ and $40 \mathrm{~mA}\left(\mathrm{CuK}_{\alpha 1}=1.5406 \AA\right)$ with $0.06^{\circ}$ step and a fixed acquisition time of $10 \mathrm{~s} / \mathrm{step}$. The catalytic powder scraped from a catalyzed CPL was deposited on a Kanthal foil and measurements were carried out in the $2 \theta$ range from $20^{\circ}$ to $60^{\circ}$. The acquisition of the whole pattern was performed for $183 \mathrm{~s}$ at room temperature. The instrumental resolution function of the diffractometer was evaluated from the pattern (10$\left.155.5^{\circ}\right)$ of the NIST SRM $660\left(\mathrm{LaB}_{6}\right)$ line profile standard. XPS measurements were performed by using an Escalab MKII (VG scientific) set-up using the magnesium monochromatic beam $(1253.6 \mathrm{eV})$ at room temperature at pressures below $8 \cdot 10^{-9}$ Torr in the analysis chamber. Core level spectra were recorded at a $50 \mathrm{meV}$ resolution. Binding energies were lined up with respect to the $\mathrm{C} 1 \mathrm{~s}$ peak at $284.6 \mathrm{eV}$.

The Membrane electrode assembly for fuel cell tests consisted in two $0.010 \mathrm{mg}_{\mathrm{Pt}} \mathrm{cm}^{-2} \mathrm{Pt} / \mathrm{CPL}$ electrodes with $5 \mathrm{~cm}^{2}$ surface area mechanically pressed on a Nafion 212 membrane at $2 \mathrm{Nm}$ torque in the cell hardware (Electrochem). No preliminary hot pressing process of electrodes against the Nafion 212 membrane (used as received from Electrochem. Inc.) was performed. 
No Nafion solution was added in the electrode catalytic layers before use. Under our testing conditions, the pressure is manually regulated with the output valves and hydrogen and oxygen are humidified by bubbling in water at $80^{\circ} \mathrm{C}$ and $40^{\circ} \mathrm{C}$, respectively. Measurements in a $5 \mathrm{~cm}^{2}$ PEMFC using pure $\mathrm{H}_{2}$ and $\mathrm{O}_{2}$ gases are performed using a ECL150/MTS 150/HSA unit (Electrochem. Inc.). The polarization curves are recorded by applying increasing current values to the cell and reading the voltage stabilization (at least $30 \mathrm{~s}$ stabilization time for each current value).

\section{Molecular Dynamics Modeling}

The MD simulations are intended to mimic the Pt-cluster growth process from Pt-atom deposition on a carbon nanoporous substrate. A realistic model for this substrate is constructed by applying a constrained reverse Monte-Carlo procedure designed to reproduce a set of high resolution transmission electron microscopy pictures. ${ }^{[35]}$ The dimensions of the model substrate are $6 \times 6 \times 6 \mathrm{~nm}^{3}$, containing 17040 atoms, corresponding to a density of 1.57 $\mathrm{g} \mathrm{cm}^{-3}$ and a porosity of $48 \%$. Periodic boundaries are applied in the lateral directions, thus exposing the top of the structure as a free surface.

2500 platinum atoms are released towards the substrate every $\Delta t=2 \mathrm{ps}$. The initial position of the Pt atom is $8 \AA$ above the substrate and with randomly chosen $\{\mathrm{x}, \mathrm{y}\}$ coordinates. $\mathrm{Pt}$ atoms interact with other Pt atoms and with the nanostructured carbon substrate atoms within a cutoff distance of $8 \AA$. The initial velocities of the incoming Pt atoms are sampled from a Maxwell-Boltzmann distribution with three most probable mean kinetic energies $\left\langle\mathrm{E}_{\text {deposit }}\right\rangle$ of $1 \mathrm{eV}, 0.1 \mathrm{eV}$ and $0.026 \mathrm{eV}$ and with randomly chosen incident angles. The mean kinetic energy $\left\langle\mathrm{E}_{\mathrm{deposit}}\right\rangle$ of the incoming atoms is calculated according to a modified Thompson formula for atoms travelling through a plasma ${ }^{[36,37]}$ over a defined target-to-substrate distance. In the case of a mean kinetic energy $\left\langle E_{\text {deposit }}\right\rangle=1 \mathrm{eV}$, the simulation corresponds to 
sputtering experiments at low argon pressure where a small amount of buffer gas only randomizes the sputtered atom velocities with little energy loss. The second case studied, $\left\langle\mathrm{E}_{\text {deposit }}\right\rangle=0.1 \mathrm{eV}$, either corresponds to resistive or e-beam evaporation, which produces a vapour at the vaporization temperature of ca. $0.1 \mathrm{eV}$. Plasma sputtering deposition at a gas pressure around $2 \mathrm{~Pa}$ also produces a vapor with mean kinetic energy around $0.1 \mathrm{eV}$. In the last case, where $\left\langle\mathrm{E}_{\text {deposit }}\right\rangle=0.026 \mathrm{eV}$, the simulation mimics a metal vapor at the temperature of $300 \mathrm{~K}$ which occurs when sputtered Pt atoms travel across an argon plasma at a pressure of around $5 \mathrm{~Pa}$.

The temperature of the substrate in all simulations is assumed to be $300 \mathrm{~K}$. The substrate temperature is controlled by applying a Berendsen heat bath, employing a relaxation time of 1.17 ps. The carbon-carbon interactions in the substrate are modeled by a Tersoff potential. ${ }^{[38]}$ The platinum-platinum interactions are modeled through an EAM potential. ${ }^{[39-43]}$ The platinum-carbon interactions are modeled using a 12-6 Lennard-Jones (LJ) potential. We used parameters that were derived by Morrow and Striolo, ${ }^{[44]}$ based on DFT calculations by Acharya et al. ${ }^{[45]}$ for the binding energy of Pt on various graphite sites. The DFT data was then used to generate a potential energy surface, to which the Lennard-Jones interaction potential was fitted. According to this parameterization, the characteristic $\mathrm{Pt}-\mathrm{C}$ interaction length is $\sigma_{\mathrm{PtC}}=1.60 \AA$ and energy, $\varepsilon_{\mathrm{PtC}}=0.1365 \mathrm{eV}$, which are significantly different from previous sets ${ }^{[46-49]}$. Indeed, we have chosen to use this new parametrization, as the previously used sets gave rise to very weak substrate bonding and the formation of Pt clusters which are invariably crystalline, contrary to our experiments (see below).

\section{Results and discussion}

The condensation coefficient of Pt onto the porous substrate is $0.83 \pm 0.02$ and does depend on the incoming kinetic energy. 
Snapshots obtained from these simulations are shown in Figure 1, for the three impact energy distributions considered here.
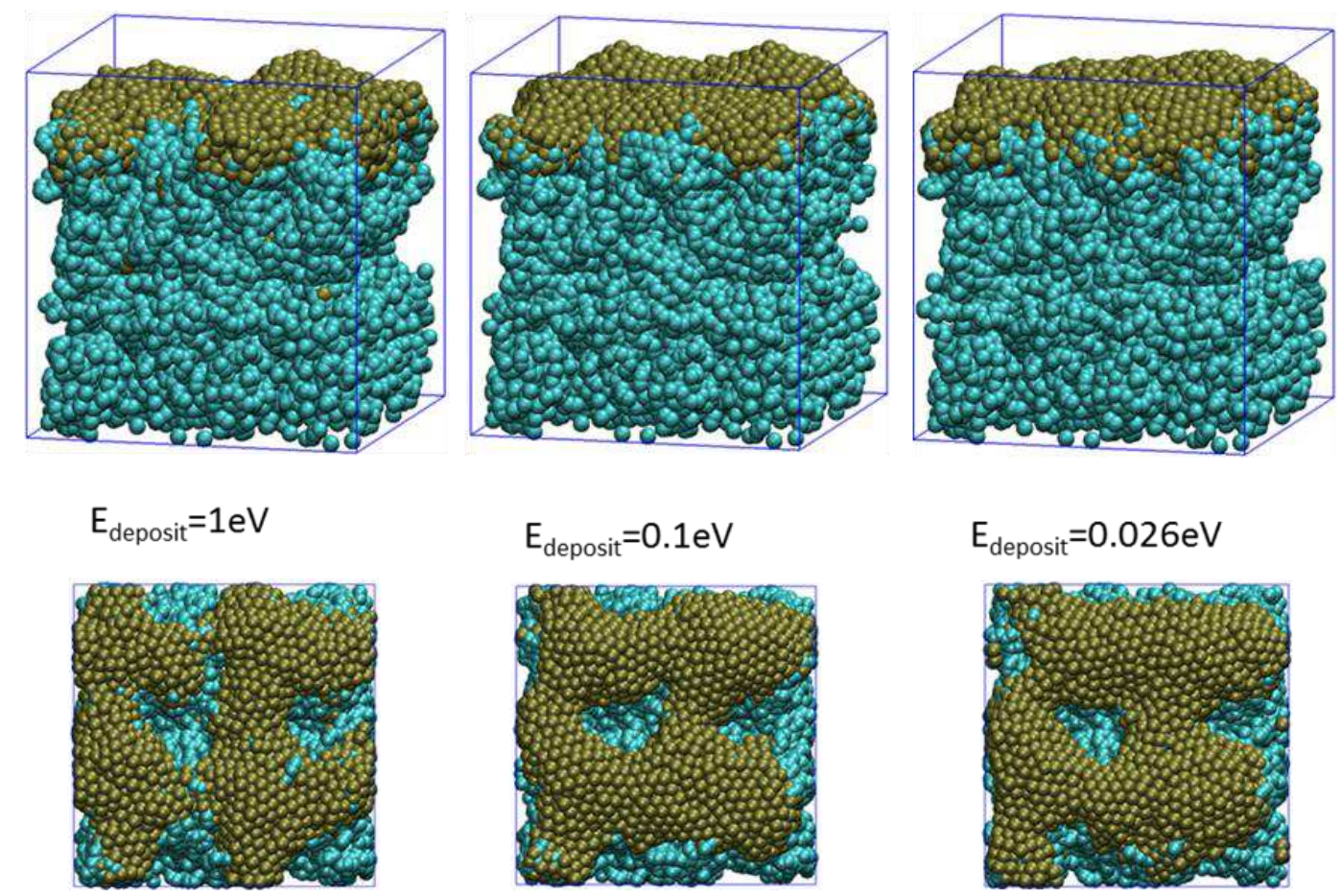

Figure 1. Snapshots of $\mathrm{Pt}$ deposition on the porous carbon substrate. The green spheres represent $\mathrm{C}$-atoms and the brownish spheres represent Pt-atoms.

It can be seen in Figure 1 that simulations result in the formation of thin film-like structures for all kinetic energies investigated. The relatively higher binding energy allows the Pt deposition to closely wet the substrate morphology. Moreover, the Pt atoms are allowed to diffuse through the pores of the substrate, resulting in an overall smoother and flatter surface morphology. This result is in agreement with experimental plasma sputtering deposition of $\mathrm{Pt}$ on porous carbon, demonstrating the Pt diffusion into the porous carbon substrate. ${ }^{[50-52]}$

The Pt concentration profiles for the three set of kinetic energy distribution centered at 0.26 , 0.1 and $1.0 \mathrm{eV}$ are plotted in Figure 2. For these three sets of calculation the concentration profile exhibits a bell shape, as in the case for thermal diffusion. When increasing the incoming kinetic energy, the concentration profile is shifted towards the in-depth of the substrate. 


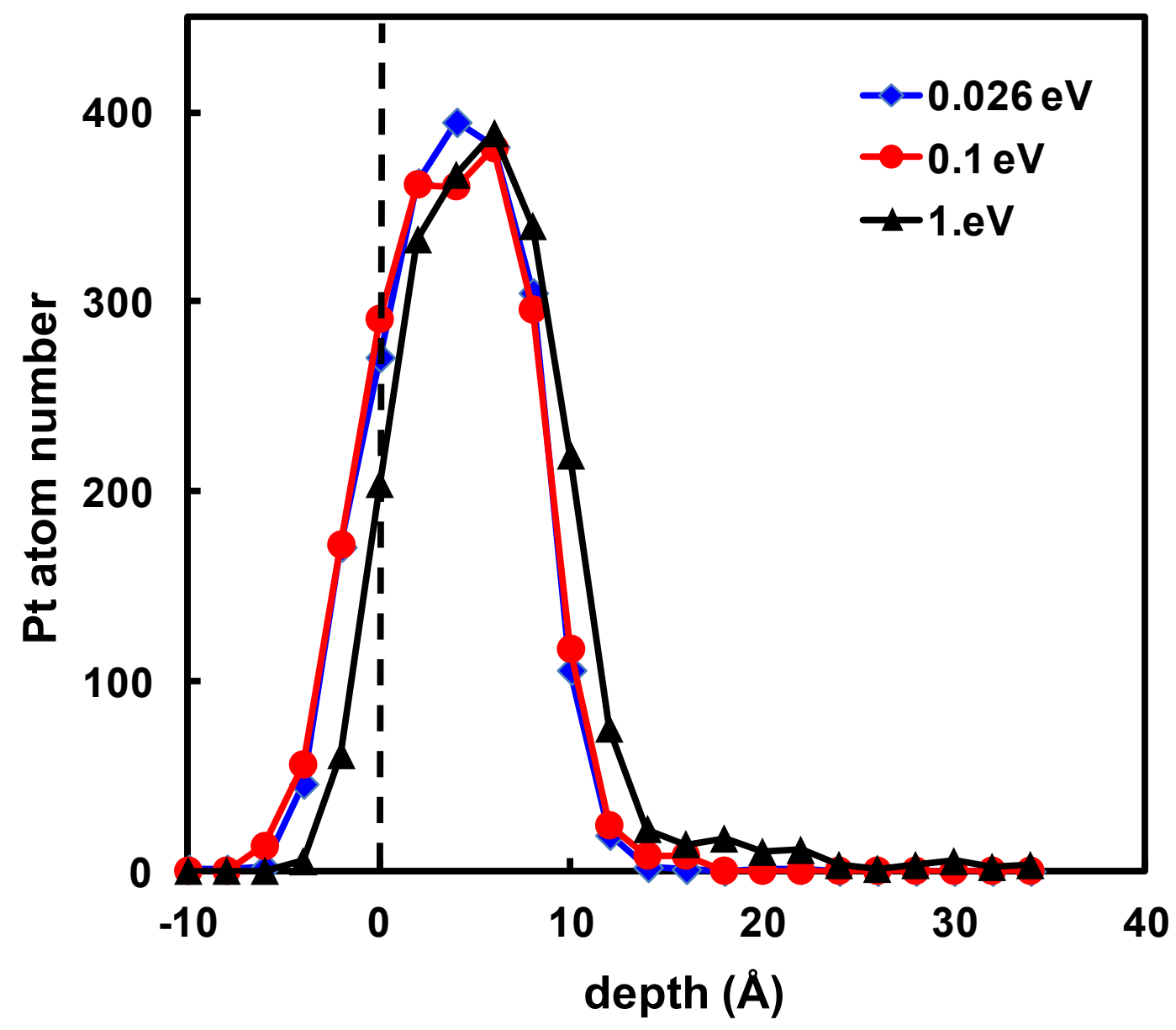

Figure 2. The Pt concentration profile for the three sets of kinetic energies. The values in the inset correspond tot he mean kinetic energy of the sampled Maxwell-Boltzmann distribution.

Radial distribution function (RDF) plots, counting the neighbors at a given distance, for the $\mathrm{Pt}$ deposits are shown in Figure 3 and detailed in Table 1. For the three kinetic energy distributions of the depositing Pt atoms investigated here, the RDF first peak is very broad. Moreover, the third and fourth peaks are overlapping for all energies, while the second peak, corresponding to $2^{\text {nd }}$ neighbor distance expected in bulk crystalline $\mathrm{Pt}$ is missing. This is due to the fact that the Pt clusters are wetting the disordered surface, such that the parallel atomic planes below and above a Pt atom (where the 2nd neighbors are lying in a face centered cubic crystal), are not defined. Consequently, the corresponding peak does not appearing in the 
RDF. Both features are representative of disorder. On the other hand, close inspection of the snapshots in Figure 1 reveals some atomic ordering, and specifically the formation of centered hexagons on the surface.

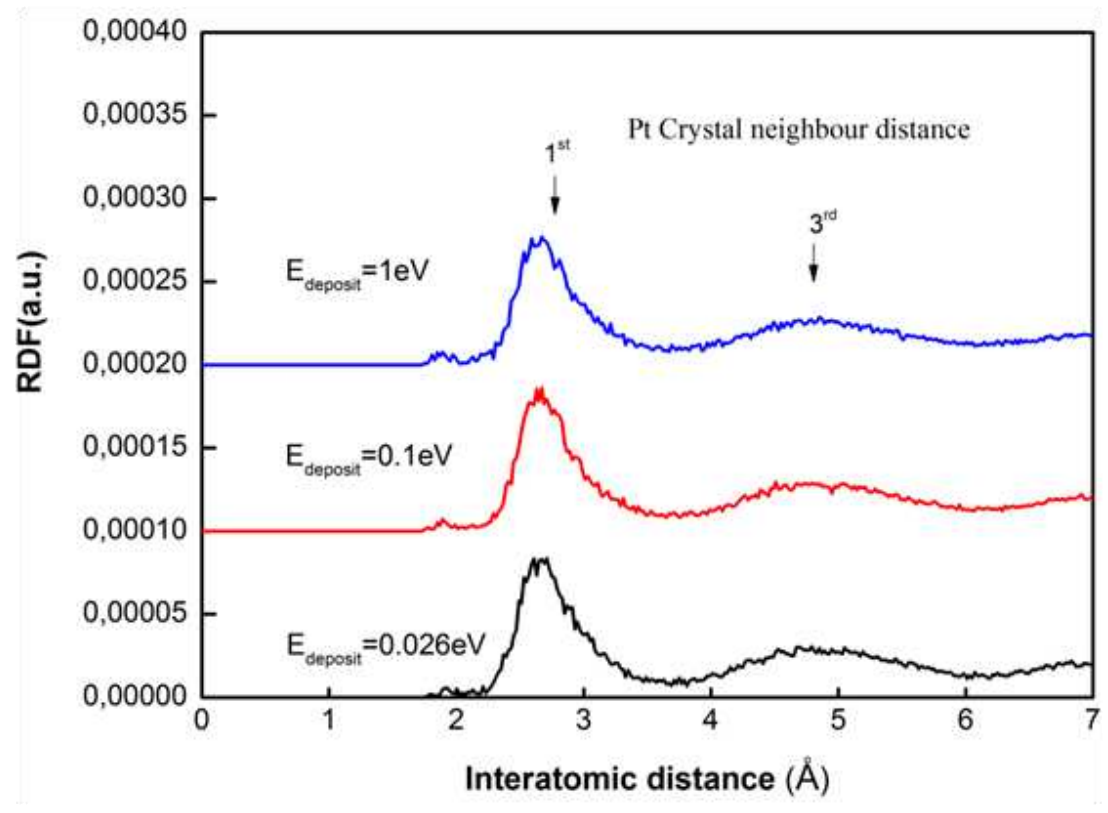

Figure 3. The calculated RDF of the Pt deposit grown on the porous carbon.

Table 1. RDF peak positions corresponding to Figure 3 of the deposited Pt structures grown on the porous carbon substrate displayed in Figure 2, and the comparison to the Pt bulk crystal values.

\begin{tabular}{lccccc}
\hline & $\begin{array}{c}1^{\text {st }} \text { neighbor } \\
(\AA)\end{array}$ & $\begin{array}{c}2^{\text {nd }} \text { neighbor } \\
(\AA)\end{array}$ & $\begin{array}{c}3^{\text {rd }} \text { neighbor } \\
(\AA)\end{array}$ & $\begin{array}{c}4^{\text {th }} \text { neighbor } \\
(\AA)\end{array}$ & $\begin{array}{c}5^{\text {th }} \text { neighbor } \\
(\AA)\end{array}$ \\
\hline Pt crystal value & 2.7746 & 3.9239 & 4.8058 & 5.5492 & 6.79 \\
$\operatorname{Pt}(1 \mathrm{eV})$ & 2.66 & - & 4.79 & - & - \\
$\operatorname{Pt}(0.1 \mathrm{eV})$ & 2.65 & - & 4.67 & - & - \\
$\operatorname{Pt}(0.026 \mathrm{eV})$ & 2.67 & - & 4.85 & - & - \\
\hline
\end{tabular}

To further resolve the the ordered/disordered state of the Pt deposits showin in Figure 1, we calculate their resulting X-ray ray diffraction (XRD) patterns. The calculated X-ray intensities vs. $2 \theta$ of the deposited Pt clusters are shown in Figure 4 and detailed in Table 2. 


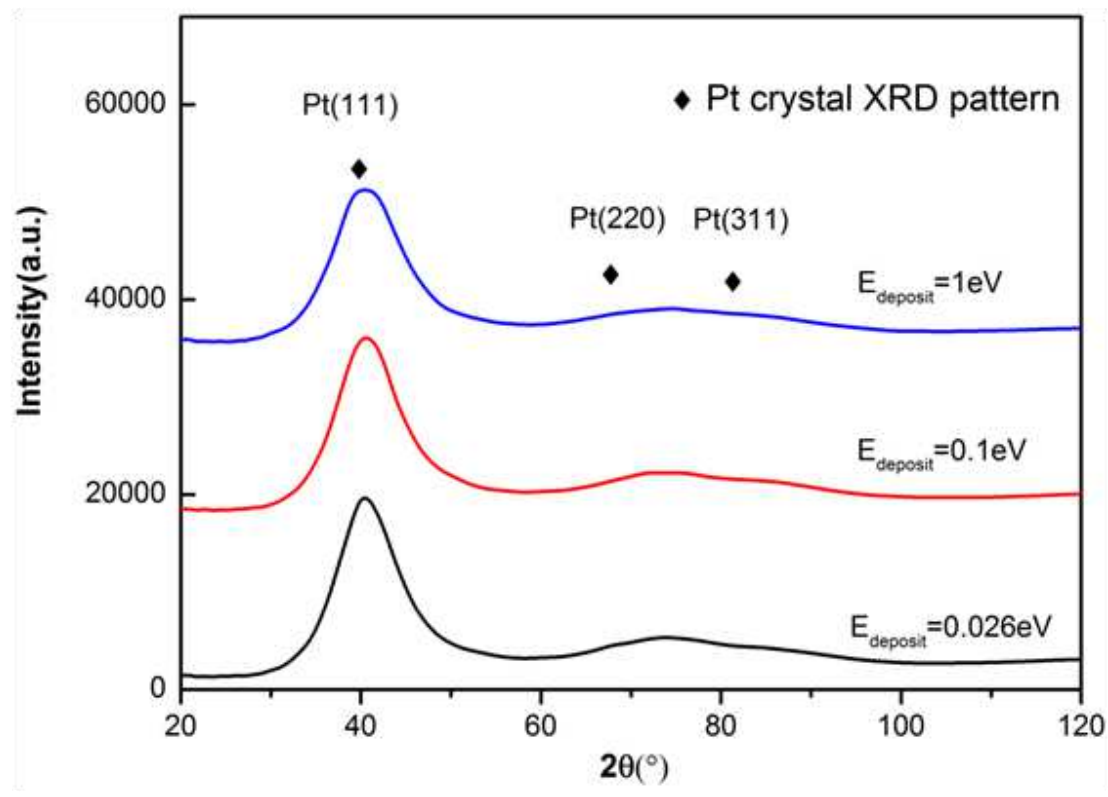

Figure 4. The simulated XRD intensities vs. $2 \theta$ of deposited Pt structures on the model porous carbon substrate. Diamond symbols give the Pt bulk positions.

It can be seen that only two broad peaks arise for each sample, which can be attributed to $\operatorname{Pt}(111)$ and $\operatorname{Pt}(220)$ orientations. This observation is consistent with some order in the plane of the surface and the fading of 2 nd and other neighbor distances.

Table 2. The $2 \theta$ position of XRD peaks for Pt crystal and simulated Pt structures (Unit: $2 \theta /{ }^{\circ}$ ).

\begin{tabular}{cccccccc}
\hline & $\operatorname{Pt}(111)$ & $\operatorname{Pt}(200)$ & $\operatorname{Pt}(220)$ & $\operatorname{Pt}(311)$ & $\operatorname{Pt}(222)$ & $\operatorname{Pt}(400)$ & $\operatorname{Pt}(331)$ \\
\hline Pt bulk crystal & 39.75 & 46.25 & 67.45 & 81.25 & 85.7 & 103.5 & 118.15 \\
$\operatorname{Pt}(1 \mathrm{eV})$ & 40.56 & ---- & 73.95 & ---- & ---- & ---- & --- \\
$\mathrm{Pt}(0.1 \mathrm{eV})$ & 40.73 & ---- & 72.8 & ---- & ---- & ---- & ---- \\
$\operatorname{Pt}(0.026 \mathrm{eV})$ & 40.69 & ---- & 74.6 & ---- & ---- & ---- & ---- \\
\hline
\end{tabular}

It has been demonstrated that it is possible to produce such amorphous Pt structure on a porous carbon by co-deposition of $\mathrm{Pt}$ and carbon using plasma magnetron sputtering. ${ }^{[50,51]} \mathrm{A}$ typical TEM image of the deposited Pt clusters is shown in Figure 5a with the related size distribution in the inset of Figure 5a, and the experimental XRD pattern recorded on such magnetron sputtered electrodes in Figure 5b. The TEM image shows very small Pt clusters of ca. $1 \mathrm{~nm}$, and the size distribution leads to an estimate of the mean size of Pt particles wetting carbon spheres of about $1.4 \mathrm{~nm}$. Note, however, that the counting is complicated due to the $\mathrm{Pt}$ 
cluster agglomeration. It is therefore likely that the bigger particles are actually agglomerated clusters rather than isolated clusters.

The XRD pattern shows no diffraction peak corresponding to the fcc structure of platinum, but only a featureless Pt background, which is consistent with the very low Pt loading (10 $\mu \mathrm{g}$ $\mathrm{cm}^{-2}$ ) and an amorphous structure. Most apparent peaks come from polytetrafluoroethylene (PTFE) particles present in the porous carbon layer acting as substrate for the deposited Pt clusters.
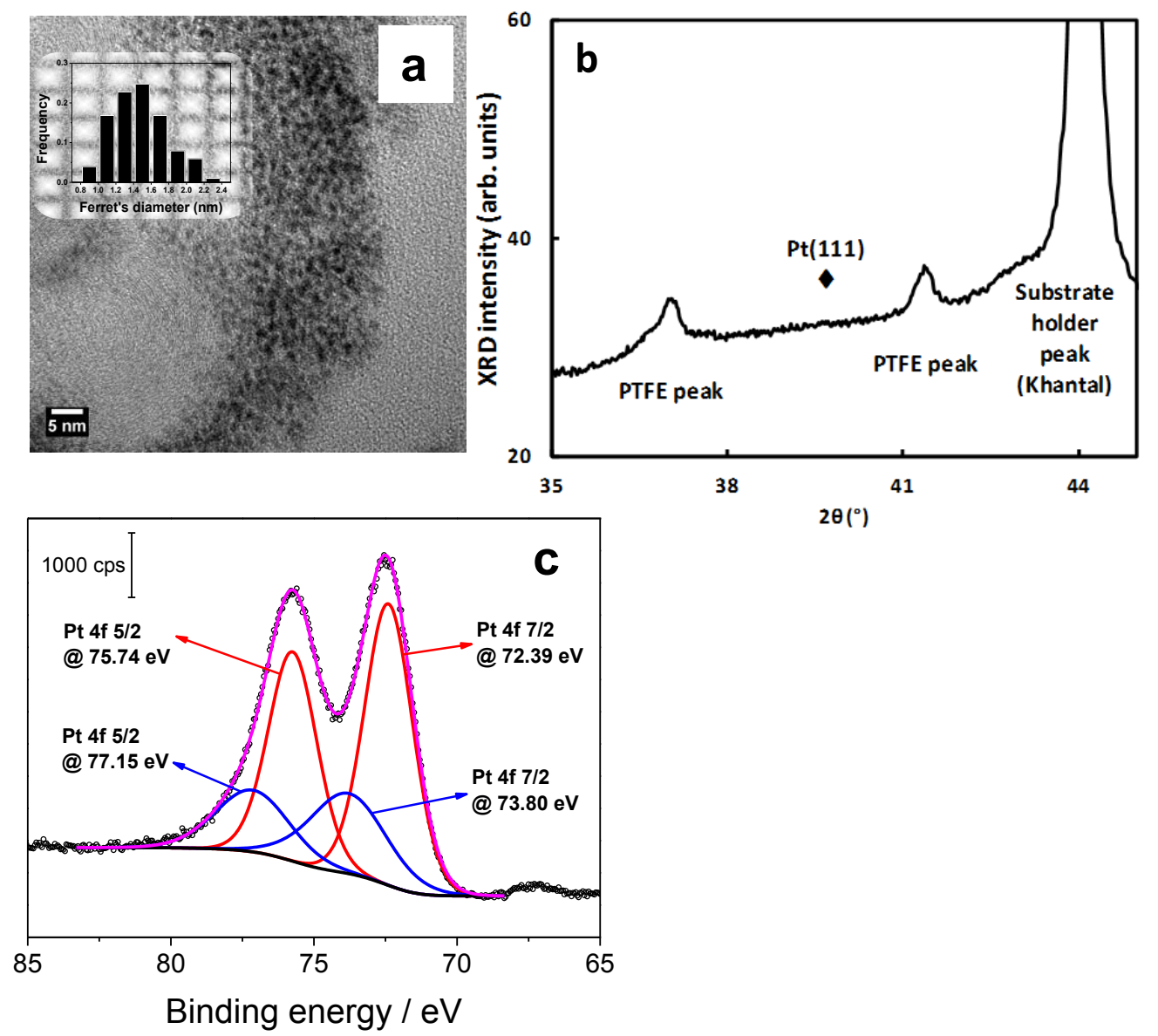

Figure 5. (a) typical TEM image of Pt nanoclusters deposited by plasma sputtering on a carbon porous layer, (b) Experimental XRD pattern showing the amorphous structure of the Pt cluster deposited onto a carbon porous layer and (c) XPS spectra of the Pt $4 \mathrm{f}$ orbital of Pt nanoclusters deposited by plasma sputtering on a carbon porous layer (loading: $10 \mu \mathrm{g}_{\mathrm{Pt}} \mathrm{cm}^{-2}$ ).

Moreover, this result is confirmed by XPS measurements (Figure 4c) showing only the presence of $\mathrm{PtO}_{\mathrm{x}} \mathrm{H}_{\mathrm{y}}$ species (Table 3) in Pt clusters, which is consistent with a very small 
particle size ${ }^{[53]}$ For Pt clusters of ca. $2.5-3.0 \mathrm{~nm}$, the shell $\mathrm{Pt}$ atoms have a +2 oxidation state, whereas the core Pt Pt atoms are metallic. ${ }^{[54]}$ The absence of metallic Pt confirmed that the size of the clusters was small enough to consider all Pt atoms as surface atoms. ${ }^{[55]}$ All these physicochemical characterizations confirm that the structure of the Pt deposit on the carbon porous layer consists of very small amorphous clusters. ${ }^{[53]}$

Table 3. XPS catalyst characterization data. The assignment of chemical species to the binding energy is based on data from the Handbook of X-ray photoelectron spectroscopy. ${ }^{[56]}$

\begin{tabular}{lcccc}
\hline & Binding energy / eV & Atomic ratio / \% & Species & Concentration ratio / \% \\
\hline Pt 4f 7/2 & 72.39 & 39.46 & Pt $(\mathrm{OH})_{2}$ & 69.06 \\
Pt 4f 5/2 & 75.74 & 29.6 & & \\
Pt 4f $7 / 2$ & 73.80 & 17.68 & PtO & 30.94 \\
Pt 4f 5/2 & 77.15 & 13.26 & & \\
\hline
\end{tabular}

As described in detail above, the calculated RDF and XRD patterns for the structures generated are typical for a more amorphous Pt structure. On the other hand, the experimental characterization data (TEM, XRD and XPS) confirm that Pt clusters sputtered on a porous carbon layer are very small and amorphous.

Such electrodes have been tested under $\mathrm{H}_{2} / \mathrm{O}_{2}$ fuel cell working conditions and have shown high performance, ${ }^{[21,52,57]}$ particularly concerning the Pt utilization efficiency which reach ca. $20 \mathrm{~kW} \mathrm{~g} \mathrm{gt}^{-1}$ as shown in Figure 6. Typical fuel cell performances of hydrogen/oxygen fed fuel cells at $80^{\circ} \mathrm{C}$, with $0.35 \mathrm{mg} \mathrm{cm}{ }^{-2} \mathrm{Pt}$ per electrode, are higher in terms of achieved power densities, ca. 1.0 to $1.2 \mathrm{~W} \mathrm{~cm}^{-2}$ with oxygen pressure between 1.0 and 3.0 absolute bars ${ }^{[58]}$, but leads to a much lower Pt utilization efficiency of ca. $2 \mathrm{~kW} \mathrm{~g}_{\mathrm{Pt}}{ }^{-1}$. However, the stability of such small particles could be an important issue for the system as a whole. On the other hand, such structures, consisting of strongly agglomerated Pt clusters (i.e., as if Pt clusters are supported by Pt clusters) could increase their stability towards corrosion (due to a higher chemical potential [59]) and minimize that of the support (due to less surface contact). 


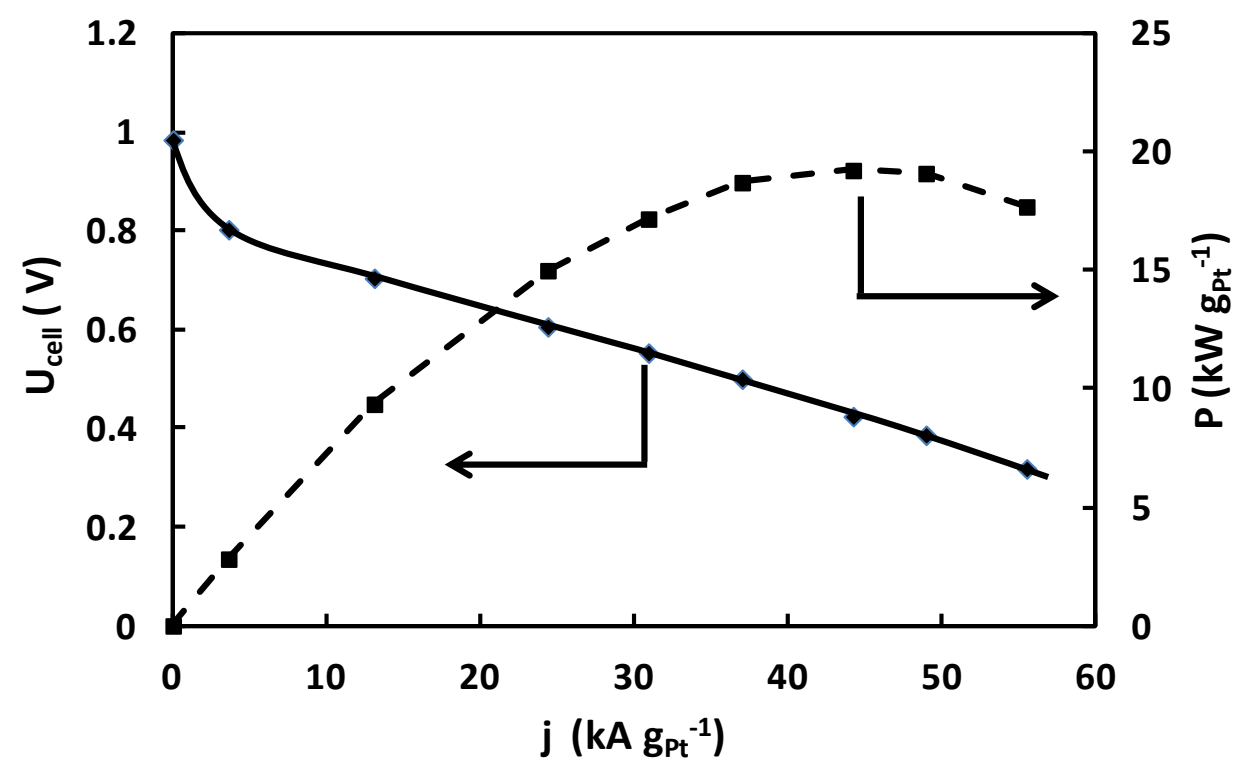

Figure 6. $\mathrm{U}_{\text {cell }}$ vs $\mathrm{j}$ and $\mathrm{P}$ vs $\mathrm{j}$ curves obtained at $70{ }^{\circ} \mathrm{C}$ with a membrane electrode assembly (MEA) consisting in a Nafion 212 membrane sandwiched between symmetrical 0.010 $\mathrm{mg}_{\mathrm{Pt}_{\mathrm{t}}} \mathrm{cm}^{-2} \mathrm{Pt} / \mathrm{CPL}$ electrodes (flow rates of $350 \mathrm{~cm}^{3} \mathrm{~min}^{-1}$ for $\mathrm{O}_{2}$ and $500 \mathrm{~cm}^{3} \mathrm{~min}^{-1}$ for $\mathrm{H}_{2}$; $\mathrm{T}_{\mathrm{O}_{2}}=40{ }^{\circ} \mathrm{C}, \mathrm{T}_{\mathrm{H}_{2}}=80{ }^{\circ} \mathrm{C}, \mathrm{P}_{\mathrm{O}_{2}}=4$ bar, $\mathrm{P}_{\mathrm{H}_{2}}=3$ bar $)$.

The power density and stability issues as well as the operating conditions of the cell may be not realistic for transport applications, where potential duty cycles and start-stop cycles may drastically deteriorate the fuel cell performances, but such low platinum loading system could be used for stationary or nomad applications.

\section{Conclusion}

In conclusion, plasma sputter deposition experiments have lead to high performance $\mathrm{Pt} / \mathrm{C}$ fuel cell electrodes. Careful analysis of the catalytic phase allowed concluding that the catalyst consists in very small amorphous platinum clusters. For understanding this phenomenon, we have carried out molecular dynamics simulation under conditions closely matching these experiments. MD simulations demonstrated the formation of Pt clusters wetting the surface and which fit closely the surface morphology, which leads to a smooth ultrathin film. In this case, only the surface structure remains crystalline to some extent. The resulting $\mathrm{Pt}$ morphologies are in agreement with experiment of Pt sputtered onto fuel cell electrodes as 
revealed by comparing the RDF and XRD simulated patterns to the experimental XRD, XPS and TEM results. This confirms that small amorphous Pt clusters are able to grow on carbon grains and to present high catalytic activity.

\section{Acknowledgements}

The financial support of the European Commission under the FP7 Fuel Cells and Hydrogen Joint Technology Initiative grant agreement FP7-2012-JTI-FCH-325327 for the SMARTCat project is gratefully acknowledged. China Scholarship Council is acknowledged for grant \#2009 60212 


\section{References}

[1] T. Muroi, Role of Precious Metal Catalysts. In Noble Metals (Eds: Yen-Hsun Su) InTech, 2012, pp. 301-334.

[2] A. Chen, P. Holt-Hindle, Platinum-Based Nanostructured Materials: Synthesis, Properties, and Applications.Chem. Rev. 2010, 110, 3767.

[3] V. Selvaraj, M. Alagar, K. S. Kumar, Synthesis and characterization of metal clustersdecorated PPY-CNT composite and their electrocatalytic oxidation of formic acid and formaldehyde for fuel cell applications. Appl. Catal. B. 2007, 75, 129.

[4] R. Narayanan, M. A. El-Sayed, Changing Catalytic Activity During Colloidal Platinum Nanocatalysis Due to Shape Changes: Electron Transfer Reaction. J. Am. Chem. Soc. 2004, $126,7194$.

[5] A. S. K. Hashmi, G. J. Hutchings, The First Gold-Catalyzed C-S Bond Formation: Cycloisomerization of $\alpha$-Thioallenes to 2,5-Dihydrothiophenes. Angew. Chem. Int. Ed. 2006, $45,1897$.

[6] Y. J. Xiong, B. Wiley, Y. N. Xia, Nanocrystals with Unconventional Shapes - A Class of Promising Catalysts. Angew. Chem. Int. Ed. 2007, 46, 7157.

[7] S. S. Gupta,N. Bandyopadhya, J. Datta, Carbon-supported platinum catalysts for direct alcohol fuel cell anode. Mater. Manuf. Process. 2006, 21, 703.

[8]W. Li, C. Liang, J. Qiu, W. Zhou, H. Han, Z. Wei, G. Sun, Q. Xin, Carbon nanotubes as support for cathode catalyst of a direct methanol fuel cell. Carbon 2002, 40, 787.

[9] S. H. Joo, S. J. Choi, I. Oh, J. Kwak, Z. Liu, O. Terasaki, R. Ryoo, Ordered nanoporous arrays of carbon supporting high dispersions of platinum clusters. Nature. 2001, 412, 169.

[10] T. R. Ralph, M. P. Hogarth, Platinum Metal Rev. Catalysis for Low Temperature Fuel Cells, Part I: The Cathode Challenges. 2002, 46, 3. 
[11] V. R. Stamenkovic, B. Fowler, B. S. Mun, G. F. Wang, P. N. Ross, C. A. Lucas, N. N. Markovic, Improved Oxygen Reduction Activity on $\mathrm{Pt}_{3} \mathrm{Ni}(111)$ via Increased Surface Site Availability. Science 2007, 315, 493.

[12] H. A. Gasteiger, S. S. Kocha, B. Sompalli, F. T. Wagner, Activity benchmarks and requirements for Pt, Pt-alloy, and non-Pt oxygen reduction catalysts for PEMFCs. Appl. Catal. B. $2005,56,9$.

[13] K. Y. Chan, J. Ding, J. Ren, S. Cheng, K. Y. Tsang, Supported mixed metal clusters as electrocatalysts in low temperature fuel cells. J. Mat. Chem. 2004, 14, 505.

[14] G. Che, B. B. Laskami, E. R. Fisher, C. R. Martin, Carbon nanotubule membranes for electrochemical energy storage and production. Nature 1998, 393, 346.

[15] Z. Q. Tian, S. H. Lim, C. K. Poh, Z. Tang, Z. Xia, Z. Luo, P. K. Shen, D. Chua, Y. P. Feng, Z. Shen, J. A. Lin, Highly Order -Structured Membrane Electrode Assembly with Vertically Aligned Carbon Nanotubes for Ultra-Low Pt Loading PEM Fuel Cells. Adv. En. Mat. 2011, 1, 1205.

[16] I. Lee, K. Y. Chan, D. L. Phillips, Growth of electrodeposited platinum nanocrystals studied by atomic force microscopy. Appl. Surf. Sci. 1998, 136, 321.

[17] V. R. Stamenkovic, B. S. Mun, M. Arenz, K. J. J. Mayrhofer, C. A. Lucas, G. Wang, P. N. Ross, N. M. Markovic, Trends in electrocatalysis on extended and nanoscale Pt-bimetallic alloy surfaces. Nature Materials, 2007, 6, 241.

[18] S. J. Hwang, S. K. Kim, J. G. Lee, S. C. Lee, J. H. Jang, P. Kim, T. H. Lim , Y. E. Sung, S. J. Yoo, Role of electronic perturbation in stability and activity of Pt-based alloy nanocatalysts for oxygen reduction. J. Am. Chem. Soc. 2012, 134, 19508-19511.

[19] J. Zhang, M. B. Vukmirovic, Y. Xu, M. Mavrikakis, R. R. Adzic, Controlling the Catalytic Activity of Platinum-Monolayer Electrocatalysts for Oxygen Reduction with Different Substrates. Angew. Chem. Int. Ed. 2005, 44, 2132. 
[20] L. Zhang, R. Iyyamperumal, D. F. Yancey, R. M. Crooks, G. Henkelman, Design of PtShell Clusters with Alloy Cores for the Oxygen Reduction Reaction. ACS Nano, 2013, 7, 9168.

[21] M. Cavarroc, A. Ennadjaoui, M. Mougenot, P. Brault, R. Escalier, Y. Tessier, J. Durand, S. Roualdès, T. Sauvage, C. Coutanceau, Performance of plasma sputtered Fuel Cell electrodes with ultra-low Pt loadings. Electrochem. Comm. 2009, 11, 859.

[22] A. C. Ferrandez, S. Baranton, J. Bigarré, P. Buvat, C. Coutanceau, Pt Particles Functionalized on the Molecular Level as New Nanocomposite Materials for Electrocatalysis. Langmuir, 2012, 28, 17832.

[23] A. C. Ferrandez, S. Baranton, J. Bigarré, P. Buvat, C. Coutanceau, Chemical Functionalization of Carbon Supported Metal Clusters by Ionic Conductive Polymer via the “Grafting From” Method. Chem. Mater, 2013, 25, 3797.

[24] R. Sellin, C. Grolleau, C. Coutanceau, J. M. Leger, S. Arrii-Clacens, S. Pronier, J. M. Clacens, Effects of Temperature and Atmosphere on Carbon-Supported Platinum Fuel Cell Catalysts. J. Phys. Chem. C 2009, 113, 21735.

[25] L. Dubau, L. Castanheira, G. Berthomé, F. Maillard, An identical-location transmission electron microscopy study on the degradation of Pt/C clusters under oxidizing, reducing and neutral atmosphere. Electrochim. Acta 2013, 110, 273.

[26] P. Urchaga, M. Weissmann, S. Baranton, T. Girardeau, C. Coutanceau, Improvement of the platinum clusters - carbon substrate interaction by insertion of a thiophenol molecular bridge. Langmuir 2009, 25, 6543.

[27] A. Tseung, S. Dhara, Loss of surface area by platinum and supported platinum black electrocatalyst. Electrochim. Acta. 1975, 20, 681.

[28] G. Clark, L. Kesmodel, Ultrahigh vacuum scanning tunneling microscopy studies of platinum on graphite, J. Vac. Sci. Technol. B 1993, 11, 131.

[29] K. Ostrikov, E. C. Neyts and M. Meyyappan, Advances in Physics 2013, 62,113 
[30] E. C. Neyts, K. Ostrikov, Z. J. Han, S. Kumar, A. C. T. van Duin, A. Bogaerts, Phys. Rev. Lett. 2013,110, 065501

[31] S. Hirano, J. Kim, S. Srinivasan, High performance proton exchange membrane fuel cells with sputter-deposited Pt layer electrodes. Electrochim. Acta, 1997, 42, 1587.

[32] A. T. Haug, R. E.White, J. Weidner, W. Huang, S. Shi, T. Stoner, N. Ranac, Increasing Proton Exchange Membrane Fuel Cell Catalyst Effectiveness Through Sputter Deposition. $J$. Electrochem. Soc. 2002, 149, A280.

[33] P. Brault, A. Caillard, A. L. Thomann, J. Mathias, C. Charles, R. W. Boswell, S. Escribano, J. Durand, T. Sauvage, Plasma sputtering deposition of platinum into porous fuel cell electrodes. J. Phys. D: Appl. Phys. 2004, 37, 3419-3423.

[34] Available at http://rsbweb.nih.gov/ij/

[35] J. Pikunic, C. Clinard, N. Cohaut, K. E. Gubbins, J. M. Guet, R. J. M. Pellenq, I. Rannou, J. N. Rouzaud, Structural modeling of porous carbons: constrained reverse Monte Carlo method. Langmuir. 2003, 19, 8565.

[36] K. Meyer, I. K. Schuller, C. M. Falco, Thermalization of sputtered atoms, J. Appl. Phys. 1981, 52, 5803.

[37] A. Gras-Marti, J. A.Valles-Abarca, Slowing down and thermalization of sputtered particle fluxes: Energy distributions. J. Appl. Phys. 1983, 54, 1071.

[38] J. Tersoff, Empirical interatomic potential for carbon, with applications to amorphous carbon. Phys. Rev. Lett. 1988, 61, 2879.

[39] M. S. Daw, M. I. Baskes, Embedded-atom method: Derivation and application to impurities, surfaces, and other defects in metals. Phys. Rev. B. 1984, 29, 6443.

[40] S. Foiles, Application of the embedded-atom method to liquid transition metals. Physical Review B. 1985, 32, 3409.

[41] S. Foiles, M. Baskes, M. Daw, Embedded-atom-method functions for the fcc metals $\mathrm{Cu}$, Ag, Au, Ni, Pd, Pt, and their alloys. Phys. Rev. B. 1986, 33, 7983. 
[42] M. S. Daw, S. Foiles, M. I. Baskes, The embedded-atom method: a review of theory and applications. Materials Science Reports 1993, 9, 251.

[43] S. Foiles, M. I. Baskes, Contributions of the embedded-atom method to materials science and engineering. Mater. Res. Bull. 2012, 37, 485.

[44] B. H. Morrow, A. Striolo, Assessing how metal-carbon interactions affect the structure of supported platinum clusters. Mol. Simulat. 2009, 35, 795.

[45] C. K. Acharya, D. I. Sullivan, C. H. Turner, Characterizing the interaction of Pt and PtRu clusters with boron-doped, nitrogen-doped, and activated carbon: Density functional theory calculations and parameterization. J. Phys. Chem. C. 2008, 112, 13607.

[46] S. Y. Liem, K. Y. Chan, Simulation study of platinum adsorption on graphite using the Sutton-Chen potential. Surf. Sci. 1995, 328, 119.

[47] S. Y. Liem, K. Y. Chan, Effective pairwise potential for simulations of adsorbed platinum. Mol. Phys. 1995, 86, 939.

[48] A. Sutton, J. Chen, Long-range Finnis-Sinclair potentials. Phil. Mag. Lett. 1990, 61, 139.

[49] D. B. Graves, P. Brault, Molecular dynamics for low temperature plasma-surface interaction studies. J. Phys. D: Appl. Phys. 2009, 42, 194011.

[50] A. Caillard, P. Brault, J. Mathias, C. Charles, R. Boswell, T. Sauvage, Deposition and diffusion of platinum clusters in porous carbon assisted by plasma sputtering.Surf. Coat. Technol. 2005, 200, 391.

[51] P. Brault, C. Josserand, J. M. Bauchire, A. Caillard, C. Charles, R. W. Boswell, Anomalous diffusion mediated by atom deposition into a porous substrate. Phys. Rev. Lett. 2009, 102, 045901.

[52] Caillard, A.; Charles, C.; Boswell R.; Brault, P. Improvement of the sputtered platinum utilization in proton exchange membrane fuel cells using plasma-based carbon nanofibers. $J$. Phys. D: Appl. Phys. 2008, 48, 1853071. 
[53] P. Brault, A. Caillard, S. Baranton, M. Mougenot, S. Cuynet, C. Coutanceau, One-step synthesis and chemical characterization of Pt $\mathrm{C}$ nanowire composites by plasma sputtering. ChemSusChem. 2013, 6, 1168.

[54] R. Sellin, J.-M. Clacens, C. Coutanceau, A thermogravimetric analysis/mass spectroscopy study of the thermal and chemical stability of carbon in the Pt/C catalytic system, Carbon 2010, 48, 2244.

[55] C. Henry C. Size Effects on Structure and Morphology of Free or Supported Clusters. In Nanomaterials and Nanochemistry (Eds: C. Bréchignac, P. Houdy, M. Lahmani) Springer, Berlin, Germany 2007, pp. 3-32.

[56] Wagner, C. D., Riggs, W. M., Davis, L. E., Moulder, J. F., Mouilenberg, G. E. Handbook of X-ray Photoelectron Spectroscopy; Perkin Elmer Corporation: Eden Prairie, MN, 1978.

[57] M. Mougenot, A. Caillard, P. Brault, S. Baranton, C. Coutanceau, High Performance Plasma Sputtered PdPt Fuel Cell Electrodes with Ultra Low Loading. Int. J. Hydrogen Energy. 2011, 36, 8429.

[58] A. J. -J. Kadjo, P. Brault, A. Caillard , C. Coutanceau , J.-P. Garnier, S. Martemianov, Improvement of proton exchange membrane fuel cell electrical performance by optimization of operating parameters and electrodes preparation, J. Power Sources 2007, 172, 613-622.

[59] J. A. S. Bett, K. Kinoshita, P. Stonehart, Crystallite growth of platinum dispersed on graphitized carbon black: II. Effect of liquid environment, J. Catal. 1976, 41, 124-133. 